\title{
i[
}

\section{Risk Analysis in the Management of Two Festivals}

\author{
Amalia Cristina Nedelcuț ${ }^{1 *}$, Răzvan Liviu Nistor ${ }^{2, ~ *}$ \\ 1,2 Babes-Bolyai University, Faculty of Economics and Business Administration \\ Cluj-Napoca, Romania \\ *Corresponding author
}

\begin{abstract}
.
This research aims to identify the potential risks in organizing two festivals which share a similar coordinate: the mediatisation of Romanian musical compositions. The Trio Transilvan Festival preserves, recovers and promotes the traditional Transylvanian creations, whereas the Cluj Modern Festival is present in the field of contemporary music as a first stage for promoting the local cultivated creation. The prevention and limitation of risk factors concerning the two events provided the motivation to organize a survey which consisted in a questionnaire applied to the organizers: institutions, managers, financial officers, staff from the arts secretariats, sponsors. Following the statistical processing through the SPPS software, we were able to establish correlations between the risk perception of the two events in relation to several potential risk factors: strategic, operational, financial, commercial, environmental, the dependence on the audience, on human resources. The results revealed that the organizers of the Cluj Modern festival identify higher risks compared to those staging the Trio Transilvan, with the prevalence of such risks determined by the insufficient human resource and the economic factors. One of the elements contributing to the perception of risk situations is the dependence of the festival's effectiveness on audience participation along with the specific venues, as environments differentiated according to the artistic offer may bring about additional risks. The assessment of the type of risk faced by the organizers of the two events is to lead towards the inclusion of the risk analysis in management practices so as to create interventions to limit their effects.
\end{abstract}

Keywords: correlation, events, music, risk factors, survey 


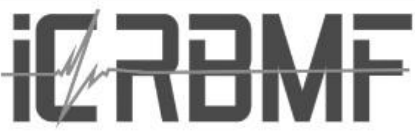

\section{Introduction}

The research which provides the foundation of cultural management on scientific bases [Moldoveanu, 2000] began during the last decades of the last century, when the organization of large-scale artistic events (such as fairs, festivals, concerts, exhibitions) required a planned and coordinated approach, to facilitate the avoidance of unexpected risks or threats. Thus, the study of artistic management become a stringent concern [Getz et al., 2010], the results of research in the field being implemented in the environment of the cultural institutions due to the need to streamline artistic and cultural activities.

Evaluating and measuring the effectiveness of a festival represents a challenge for specialists, while data collection has also become extremely important (Hiller, 2016). In most cases, statistical surveys are based on qualitative and quantitative analyses and evaluations, which assess the economic impact (the use of coefficients and cost / benefit analysis, respectively), but also the relevance of the social impact (Song et al., 2014). The severity parameters and the consequences of the failure of public events are frequently studied (Frost \& Laing, 2015), mainly due to the extent to which they are organized, but also because of the increased frequency of risks that may lead to the failure of public events.

By conducting a survey on some groups involved in organizing the two events, the present paper aims to assess the risk of two festivals organized in the Transylvania area, both of which promote Romanian music through different genres (cultivated music and traditional folklore) in Cluj county. The Cluj Modern festival takes place once every two years, since 1995, being organised by the "Gheorghe Dima" Music Academy in Cluj-Napoca, in collaboration with the "Transilvania" Philharmonic, the Union of Romanian Composers and Musicologists, several European cultural centres active in this city, with the support of the Ministry of Culture, and the local and county institutions, for each edition. The festival is attended especially by professional musicians, both the interpreters and the audience being receptive to the novelties manifested in contemporary cultivated creation (Nedelcut, 2017). The traditional Romanian music festival Trio Transilvan is a special feature of Transylvania, for the uniqueness and authenticity of the repertoire, and ever since 1983 it received the financial and organizational support of the Ministry of Culture, the Cluj Institute of Folklore and Cultural Centre (Nistor \& Nedelcut, 2017). These institutions endeavoured to preserve the folklore specific to this type of ensemble, and the UNESCO Certification Committee is currently "analysing" that this unique and representative element of the area be included in the World Heritage of Humanity.

\section{Methodology}

The risk identification process is considered a first important step in risk management, by delineating potential risk factors to avoid situations that make it difficult to carry out planned activities in the unfolding of an event. To this end, the organizers of the Trio Transilvan and Cluj Modern festivals applied a survey containing 5 sets of questions with different levels of

evaluations, which was answered by the persons in charge from the cultural institutions involved and by the financiers. For the question: "Is your institution confronted with the 


\section{IF}

following situations in organizing the Festival?," risk situations were identified on different coordinates; subsequently the results were correlated and risk analyzes were carried out, which will be included in the organizing strategies of future editions. In the case of each festival, the study was conducted on a sample of 30 respondents, therefore the results can be considered statistically significant.The answers given to the questionnaire had 3 variants: 1 / reduced risk, 2 / medium risk , 3 / high risk and the conclusions were presented by graphs for each risk situation:

\section{Results}

1. The strategic risk is considered a "major" risk, which may have consequences for an event through the impact of unpredictable actions that may occur at the time of the event (Ciocoiu, 2008). In the case of the two festivals was tested the hypothesis of the inadequate event planning, according to Table 1 (comparison of the mean in both cases) and the analysis found that the organizers of the Trio Transilvan festival consider that an inadequate programming of the event presents an average risk, but less than considered by the organizers of the Cluj Modern festival.

Table 1: Strategic risk comparison for the two festivals

\begin{tabular}{|l|r|r|r|r|r|}
\hline & $\mathrm{N}$ & Minimum & Maximum & Mean & Std. Deviation \\
\cline { 1 - 4 } $\mathrm{A} 1 \mathrm{G}$ & 30 & 1.00 & 3.00 & 2.3667 & .55605 \\
$\mathrm{~A} 1 \mathrm{CM}$ & 30 & 2.00 & 3.00 & 2.5000 & .50855 \\
Valid N (listwise) & 30 & & & & \\
\hline
\end{tabular}

Source: own projection, using SPSS

Figure 1 graphically compares the respondents' responses in estimating a strategic risk:

Figure 1: Strategic risk comparison for the two festivals 


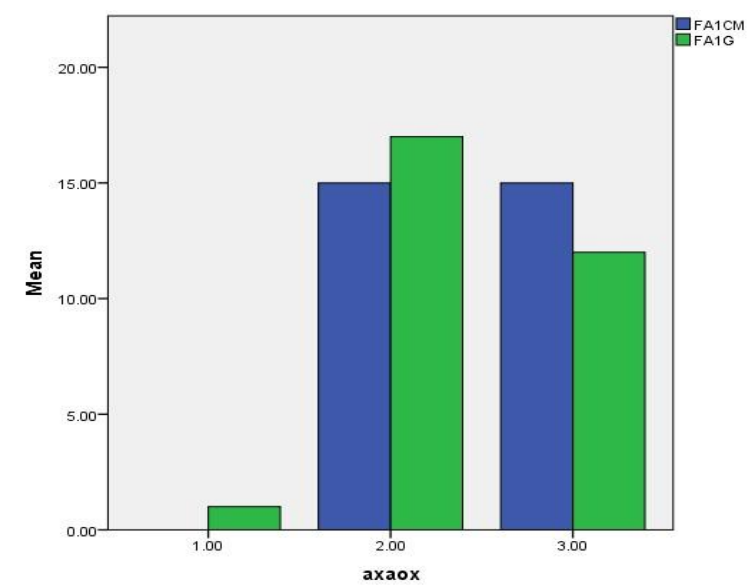

Source: made by author based on data from questionnaires

2. The risk of customer dependency is an important perspective in planning a festival, especially for those events where the organization is in a relationship of economic dependence with the audience (Van Winkle, 2014). From the perspective of the organizers of the Trio Transilvan and Cluj Modern festivals, where the organizing entities are directly controlled by the central administration or function in close connection with it, the following results (Table 2) were found: the organizers of the Trio Transilvan festival consider the dependence on clients less relevant than those of Cluj Modern, the location of the festival being an obvious advantage (Edwards, 2012) which the event organizers manage properly, showing a relatively low level of interest for this type of risk:

Table 2: Comparison of customer dependency risk for the two festivals

\begin{tabular}{|l|r|r|r|r|r|}
\hline & $\mathrm{N}$ & Minimum & Maximum & Mean & Std. Deviation \\
\cline { 1 - 3 } $\mathrm{A} 2 \mathrm{G}$ & 30 & 1.00 & 3.00 & 2.0667 & .58329 \\
$\mathrm{~A} 2 \mathrm{CM}$ & 30 & 1.00 & 3.00 & 2.3667 & .55605 \\
& & & & \\
Valid N (listwise) & 30 & & & & \\
\hline
\end{tabular}

Source: own projection, using SPSS

The comparison of response values is shown in Figure 2.

Figure 2. Comparison of customer dependency risk for the two festivals 


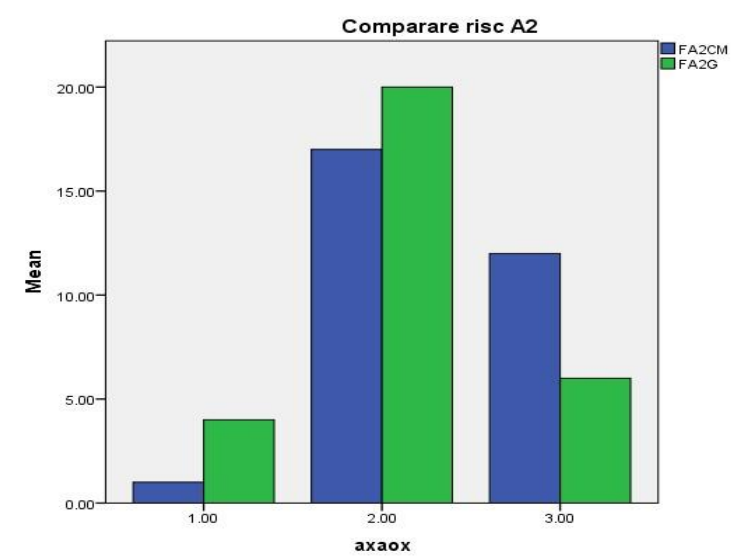

Source: made by author based on data from questionnaires

3. The operational risk is generally caused by a lack of technical capacity or logistics that is inconsistent with the activities carried out in a festival (Reid, 2011). It is important to delineate the causes (which may fall within the domain of financial resources or inadequately qualified staff) that determine the operational risk, as well as the estimated impact of this type of risk. According to Table 3, the organizers of the two studied events are differently concerned about the occurrence of the operational risk, as data indicate a lower level of interest for the Transylvanian Trio festival compared to the Cluj Modern, the graph of this situation being illustrated in Figure 3.

Table 3: Operational risk comparison

\begin{tabular}{|l|r|r|r|r|r|}
\hline & $\mathrm{N}$ & Minimum & Maximum & Mean & Std. Deviation \\
\cline { 1 - 4 } $\mathrm{A} 3 \mathrm{G}$ & 30 & 1.00 & 3.00 & 1.7333 & .78492 \\
$\mathrm{~A} 3 \mathrm{CM}$ & 30 & 1.00 & 3.00 & 2.2000 & .76112 \\
Valid N (listwise) & 30 & & & & \\
\hline
\end{tabular}

Source: own projection, using SPSS

Figure 3. Operational risk comparison for the two festivals 


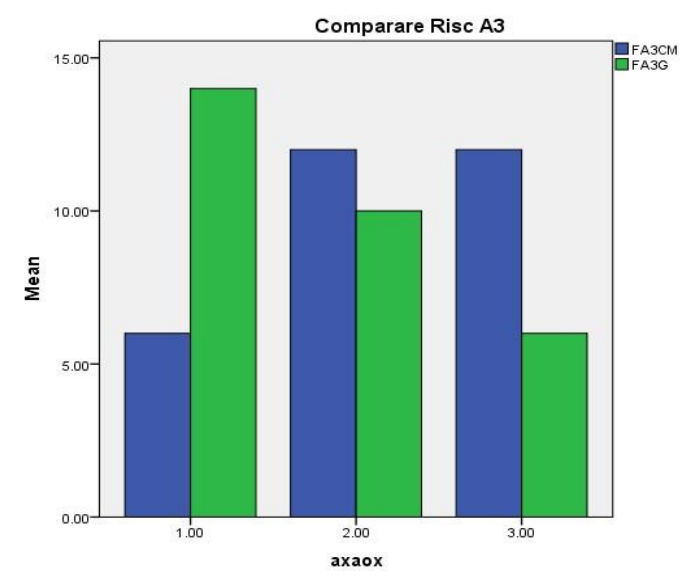

Source: made by author based on data from questionnaires

4. The human resource risk - proper management of staff, from organizers to volunteers, is a primary requirement (Wilson et al., 2017), the human resource being considered an essential source of risk situations. Issues may also arise in relation to the professional qualities of the human resource; the assessment of the potential competence of each individual may clearly bring about efficiency in the performance of artistic events. In estimating the possibility of manifesting an organizational risk related to human resources, the range of the activities carried out within the two festivals determined different attitudes in the survey evaluation: comparing the collected data we notice (Table 4) that the organizers involved in Cluj Modern are more concerned with the possible risk regarding human resources than those at Trio Transilvan. We must mention that in the first case, the diversity of activities (first performance concerts, symposia, master classes) determined the organization of events with a large number of volunteers, and in the case of the festival organized in Gherla, a small town in Cluj County, the motivation of the performers to participate at a high level in the instrument trio competition facilitates the repetitive performance of the actions, which have a low level of investment in the sphere of the human resource. Figure 4 illustrates the organizers' view on a potential human resource risk: Table 4: T Operational risk comparison

5.

\begin{tabular}{|l|r|r|r|r|r|}
\hline & $\mathrm{N}$ & Minimum & Maximum & Mean & Std. Deviation \\
\cline { 1 - 4 } $\mathrm{A} 4 \mathrm{G}$ & 30 & 1.00 & 3.00 & 1.7333 & .69149 \\
$\mathrm{~A} 4 \mathrm{CM}$ & 30 & 1.00 & 3.00 & 2.1000 & .84486 \\
Valid N (listwise) & 30 & & & & \\
\hline
\end{tabular}

Source: own projection, using SPSS

Figure 4. Operational risk comparison for the two festivals 


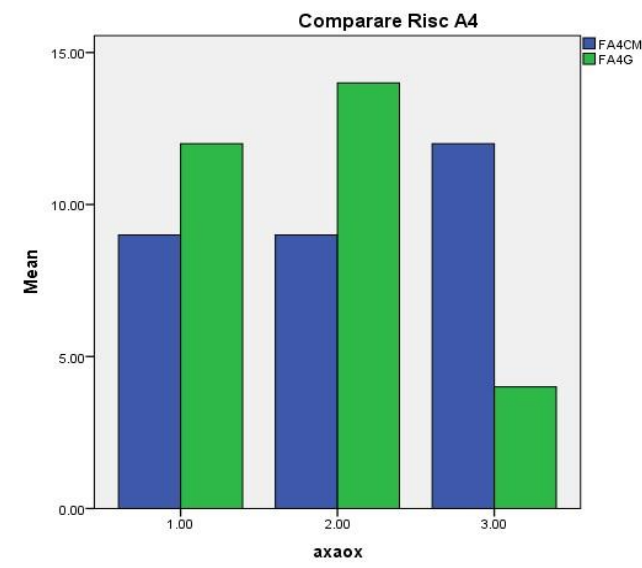

Source: made by author based on data from questionnaires

6. The financial risk is often encountered in the organization of an artistic festival, most often manifested by overcoming organizational costs. In such cases, there is an economic risk that may affect the achievement of the estimated objective and which usually results in a change in the volume of activities. Changes in the artistic process, but especially in the quality of the event, may then occur. Due to the fact that changes can be made to the cost component, the risk may lead to a decrease in the achievement of the planned results. Table

5 and Figure 5, respectively, contain information indicating that the organizers of the contemporary music festival are more concerned about the possible risk of overstating the costs, as a result of the internationalization of the event, and of the involvement of foreign artists in the interpretation of Romanian music.

Table 5: Financial risk comparison

\begin{tabular}{|l|r|r|r|r|r|}
\hline & $\mathrm{N}$ & Minimum & Maximum & Mean & Std. Deviation \\
\cline { 1 - 4 } A5G & 30 & 1.00 & 3.00 & 1.6667 & .66089 \\
A5CM & 30 & 1.00 & 3.00 & 2.3000 & .65126 \\
Valid N (listwise) & 30 & & & & \\
\hline
\end{tabular}

Source: own projection, using SPSS

Figure 5. Financial risk comparison for the two festivals 


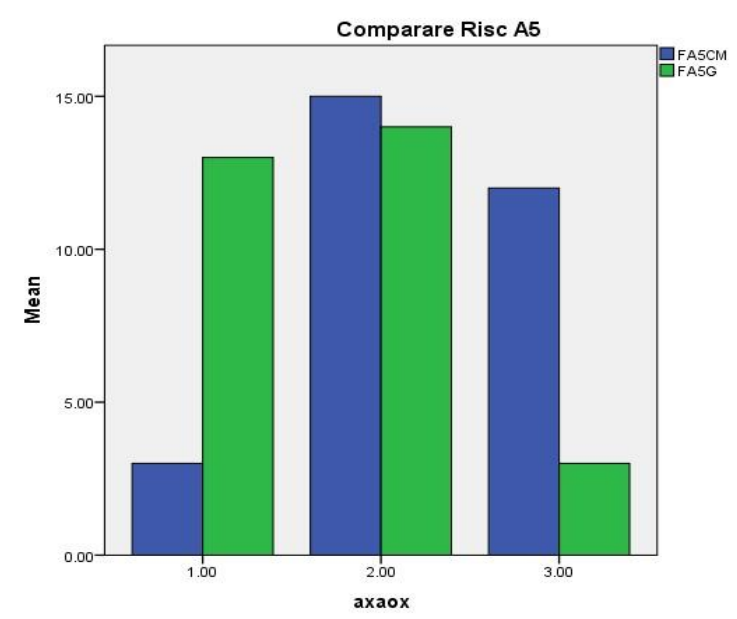

Source: made by author based on data from questionnaires

6. The compliance risk consists of ignorance and non-observance of laws and regulations, which could endanger the reputation of artists or compromise the funding of the event or even the event itself. As can be seen in Table 6 and Figure 6, the organizers of both festivals consider this kind of risk as "minimal," as institutions that carry out cultural activities act in accordance with the law of copyright.

Table 6: Compliance risk comparison

\begin{tabular}{|l|r|r|r|r|r|}
\hline & $\mathrm{N}$ & Minimum & Maximum & Mean & Std. Deviation \\
A6G & 30 & 1.00 & 3.00 & 1.5333 & .62881 \\
A6CM & 30 & 1.00 & 3.00 & 1.9000 & .71197 \\
Valid N (listwise) & 30 & & & & \\
\hline
\end{tabular}

Source: own projection, using SPSS

Figure 6. Compliance risk comparison for the two festivals 


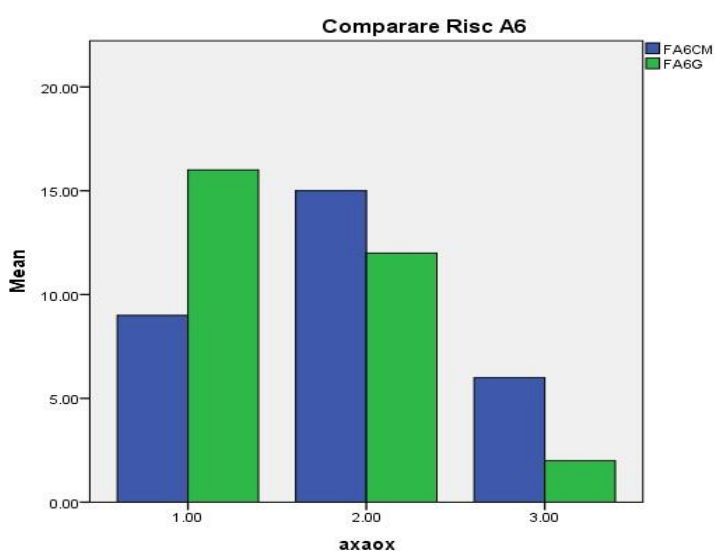

Source: made by author based on data from questionnaires

7. The commercial risk has been equated in festivals with an inadequate impact on the audience, the consequences of this risk being significant, as it may cause payment delays, blocked money, or sometimes substantial losses. In this situation, the organisers must prevent the consequences of insufficient management. The study conducted on the two festivals indicated that there was little concern for optimizing the relationship between the financial structures and those responsible for promoting and selling events, as the festival organizers considered this type of risk as below average. (Table 7, Figure 7):

Table 7: Commercial risk comparison

\begin{tabular}{|l|r|r|r|r|r|}
\hline & $\mathrm{N}$ & Minimum & Maximum & Mean & Std. Deviation \\
\cline { 1 - 4 } A7G & 30 & 1.00 & 3.00 & 1.6000 & .67466 \\
A7CM & 30 & 1.00 & 3.00 & 1.9667 & .71840 \\
Valid N (listwise) & 30 & & & & \\
\hline
\end{tabular}

Source: own projection, using SPSS

Figure 7. Commercial risk comparison for the two festivals

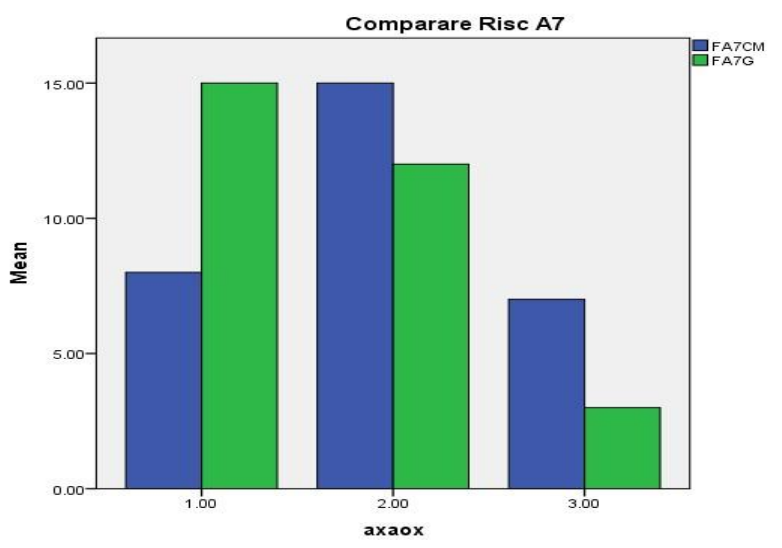

Source: made by author based on data from questionnaires 
8. The environmental risk is the situation which, in case it occurs, generates an unfavourable effect on the unfolding of the event. This type of risk may have internal causes (determined by human activity / inactivity) or external, manifested independently of the human will.

Although there are environmental indicators recorded at national, regional level, for both festivals this type of risk is considered to be low (Table 8, Figure 8):

Table 8: Environmental risk comparison

\begin{tabular}{|l|r|r|r|r|r|}
\hline & $\mathrm{N}$ & Minimum & Maximum & Mean & Std. Deviation \\
\cline { 1 - 4 } $\mathrm{A} 8 \mathrm{G}$ & 30 & 1.00 & 3.00 & 1.3000 & .59596 \\
$\mathrm{~A} 8 \mathrm{CM}$ & 30 & 1.00 & 3.00 & 1.5000 & .62972 \\
Valid N (listwise) & 30 & & & & \\
\hline
\end{tabular}

Source: own projection, using SPSS

Figure 8 Environmental risk comparison for the two festivals

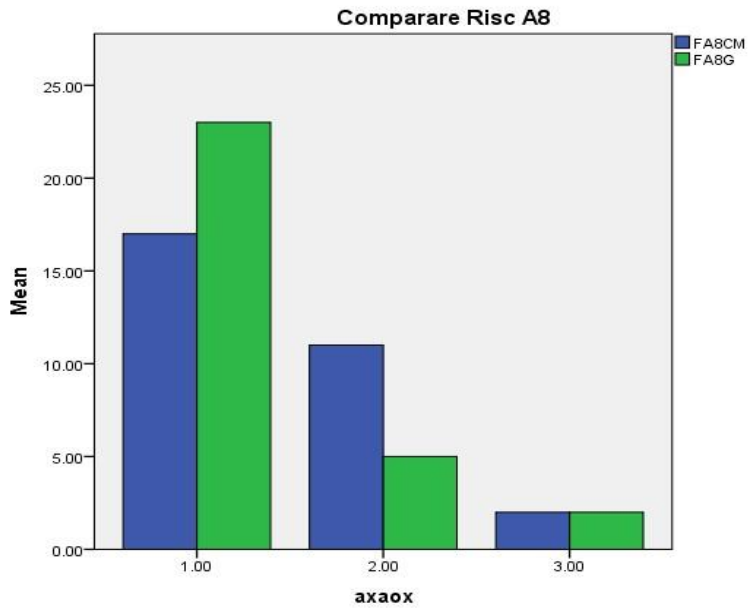

Source: made by author based on data from questionnaires 
9. For the risk of substitute products / services, there was a low risk for both festivals, which are organized and promoted on the idea of their authenticity, uniqueness in the Romanian artistic field. The Trio Transilvan festival is considered to recover an endangered traditional folk music vein, in the form of the instrumental trio ensemble, whereas the Cluj Modern festival promotes a local, contemporary and professional repertoire. Since each festival has unique features, it is difficult to produce events on the same theme that meet the same consumption need (as an alternative or that can replace this type of manifestation).

Table 9: Comparison of the risk of substitute products / services

\begin{tabular}{|l|r|r|r|r|r|}
\hline & $\mathrm{N}$ & Minimum & Maximum & Mean & Std. Deviation \\
\cline { 1 - 4 } A9G & 30 & 1.00 & 3.00 & 1.2667 & .52083 \\
A9CM & 30 & 1.00 & 3.00 & 1.3667 & .71840 \\
Valid N (listwise) & 30 & & & & \\
\hline
\end{tabular}

Source: own projection, using SPSS

Figure 9. Comparison of the risk of substitute products / services for the two festivals

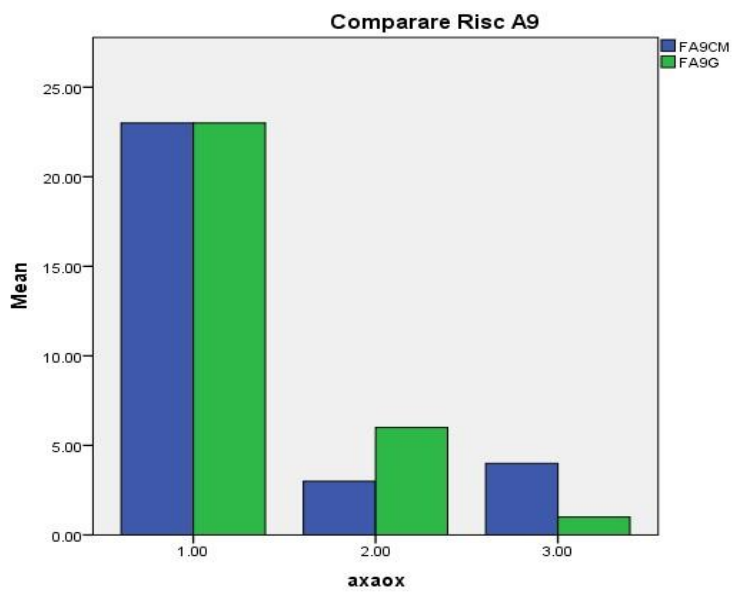

Source: made by author based on data from questionnaires 


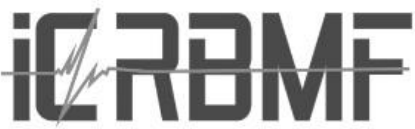

\section{Conclusions}

In order to evaluate which of the two festivals is subject (for various reasons) to an increased risk, the mean value of the answers to the 9 questions corresponding to this set of data was calculated. The result is presented in Tables 10 and 11:

Table 10: Descriptive Statistics

\begin{tabular}{|l|c|c|c|c|c|}
\hline & $\mathrm{N}$ & Minimum & Maximum & Mean & Std. Deviation \\
\hline MEDAG & 9 & 1.27 & 2.37 & 1.6963 & .34779 \\
Valid N (listwise) & 9 & & & & \\
\hline
\end{tabular}

Source: own projection, using SPSS

Table 11: Descriptive Statistics

\begin{tabular}{|l|c|c|c|c|c|}
\hline & $\mathrm{N}$ & Minimum & Maximum & Mean & Std. Deviation \\
\hline MEDACM & 9 & 1.37 & 2.50 & 2.0222 & .38441 \\
Valid N (listwise) & 9 & & & & \\
\hline
\end{tabular}

Source: own projection, using SPSS

Conclusively, in the case of the Trio Transilvan festival, the mean of the answers regarding the risk is 1.6963, and in the case of Cluj Modern it is higher, of 2.0222. Moreover, for each risk situation, it was noticed that the organizers of Modern Cluj identify an increased level of risk compared to those of Trio Transilvan. The explanation for this result may be related to:

- the breadth of the festival;

- the location of the festival, the city of Cluj, where the Cluj Modern festival takes place, is characterized by an intense cultural life, whereas Gherla is a town with few artistic resources and events of this kind;

- the duration of the event and the human resource involved in organizing the Cluj Modern festival is more extensive;

- the number of attendees is difficult to estimate for the festival mentioned above.

For future editions, it is required to include risk treatment issues in the management practices and to take risk-prevention decisions throughout the entire lifecycle of the projected activities in festivals.

\section{References}


[1] Ciocoiu, N. (2008). Managementul riscului. Teorii, practici, metodologii. Editura ASE, Bucuresti.

[2] Edwards, R., 2012. Gympie's country music Muster:Creating a cultural economy from a local tradition. Journal of Rural Studies, vol. 28, pp. 517-527.

[3] Frost, W. and Laing, J. (2015). Avoiding burnout: the succession planning, governance and resourcing of rural tourism festivals. Journal of Sustainable Tourism, vol.23, pp. 1-20.

[4] Getz D., Andersson T.D. and Carlsen J. Festival management studies. International Journal of Event and Festival Management, vol. 1, pp. 29-59.

[5] Hiller R. Scott. (2013). The importance of quality: How music festivals achieved commercial success. Journal of Cultural Economics, August 2016, vol. 40 Issue 3, pp. 309334. [6] Moldoveanu, M. (2000). Managementul culturii. Editura Expert, Bucureşti.

[7] Nedelcut, N. (2017). The Cluj Modern contemporary music festival analyzed by its organizer, Ph.D. professor Adrian POP. Studia Musica, vol. 10, issue nr.2, pp. 7-15 pp.

[8] Song Z., Xing L. and Chathoth P.K. (2014). The effects of festival impacts on support intentions based on residents' ratings of festival performance and satisfaction: a new integrative approach. Journal of Sustainable Tourism, vol. 23, pp. 316-337.

[9] Nistor, R.L and Nedelcut, A.C. (2017). Evaluating the promotion of two music events. Bulletin of the Transilvania University of Brașov, vol. 10, issue 2, pp.73-84.

[10] Reid, S. (2011). Event stakeholder management: developing sustainable rural event practices. International Journal of Event and Festival management, vol.2, issue 1, pp. 20-36.

[11] Van Winkle C.M. and Woosnam K.M. (2014). Sense of community and perceptions of festival social impacts. International Journal of Event and Festival Management, vol. 5, pp. 22-38.

[12] Wilson J., Arshed N. and Shaw E. (2017). Expanding the Domain of Festival Research: A Review and Research Agenda. International Journal of Management Reviews, vol. 19, issue 2, pp. 195-213. 